\title{
Rapport annuel 2006
}

Au cours de l'année sous revue, la Caisse de secours des médecins suisses a accordé son soutien à 31 médecins tombés malgré eux dans le besoin (ils étaient 33 en 2005), ainsi qu'aux proches et descendants de consœurs et de confrères décédés.

Pendant la même période, la Caisse a cessé d'apporter son aide à sept personnes. Toujours en 2006, cinq nouveaux cas sont venus s'ajouter à la liste des bénéficiaires: deux personnes ont obtenu une aide unique et trois personnes nécessiteront probablement un soutien pendant une longue période.

La somme globale des contributions versées s'est élevée en 2006 à Fr. 320200.- contre Fr. 330 600.- l'année précédente.

Les recettes en provenance de dons s'élèvent à Fr. 104203.-. Elles ont été nettement inférieures à celles de l'année précédente (2005: Fr. 253 032.-).

En vertu des dispositions du Règlement de fondation, la Caisse de secours ne peut accorder aucun prêt. Le montant maximal de secours pouvant être versé par année est de Fr. 12000.-. Les bénéficiaires ne sont pas tenus de restituer l'aide financière. Il est d'autant plus réjouissant que des personnes ayant pu se tirer d'affaires grâce à un soutien financier, se souviennent de la Caisse de secours et décident de lui restituer le montant obtenu. En 2006, un montant de Fr. 24000.qu'elle avait versé à titre de secours lui a été restitué avec un don de Fr. 1000.-!

La différence négative entre les recettes en provenance de dons et les contributions versées a pu être comblée grâce à une évolution favorable de la Bourse et aux gains qui en ont résulté. La somme de Fr. 82000.- a été comptabilisée sous forme de provisions sur titres en vue de futures «années maigres». Le supplément de recettes est ainsi de Fr. 3750.--

La fortune de la fondation est constituée par un mélange d'obligations et d'actions satisfaisant aux prescriptions de la prévoyance professionnelle (LPP). Le compte d'exploitation, le bilan et la gestion de la fortune sont révisés chaque année par l'autorité de surveillance des fondations du Département de justice du canton de Bâle-Ville.

Les dons individuels inférieurs à Fr. 500.forment l'essentiel du capital de notre fondation. Par souci de réduire les frais administratifs au strict minimum, nous renonçons toutefois à remercier personnellement les donateurs. Qu'ils veuillent trouver ici l'expression de notre vive gratitude!

MM. F. Hufschmid et R. Jucker, réviseurs, ont examiné les comptes annuels de la Caisse de secours et constaté que la comptabilité était tenue dans les règles. Nous saisissons l'occasion pour leur exprimer nos vifs remerciements. Pour plus de détails, le lecteur se référera au compte d'exploitation et au bilan publiés ci-après.

Suite à sa désignation au poste de médecinchef de l'hôpital Zollikerberg, le Dr L. T. Heuss, privat-docent, a démissionné, à fin 2006, du Conseil de fondation de la Caisse de secours dont il était membre. Les membres de la commission le félicitent pour sa nomination et le remercient de son engagement en faveur de la Caisse de secours durant les années passées.

Le Dr Susanna Stöhr lui succède en qualité de représentante du Comité central de la FMH au Conseil de fondation de la Caisse de secours des médecins suisses, après avoir élue à cette fonction.

Nos sincères remerciements vont également au Dr W. Zutter ainsi qu'à MM. J. Kobler et W. Mahrer de la Banque La Roche \& Co pour la tenue de la comptabilité et la gestion de la fortune.

Le Conseil de fondation de la Caisse de secours des médecins suisses:

Dr U. Leibundgut, président

Dr S. Stöhr, membre du Comité central de la FMH

Dr W. Zutter, trésorier

Compte postal de la Caisse de secours des médecins suisses: 40-644-3 Bâle. 
Tableau

Comptes annuels pour 2006 (en francs).

\section{Bilan au 31 décembre 2006}

Compte Banque La Roche

Compte UBS

Compte postal

Débiteurs impôt anticipé

Placements financiers

Titres

Compte de régulation des actifs

Provisions sur titres

Fortune au 31 décembre 2006

Dr.-J.-Ambühl-Stiftung

Dr.-J.-Genhard-Stiftung

Dr.-J.-B.-Wutz-Stiftung

Caisse de secours au $1^{\text {er }}$ janvier 20062341040.83

Liquidation «Fürsorgefonds Medisuisse»

Augmentation de la fortune

\section{Compte d'exploitation 2006}

Dons

Revenu du capital

Restitution d'une contribution accordée jadis

Gains boursiers réels sur titres

Gains boursiers Comptes en monnaie étrangère

Contributions de secours

Frais bancaires et d'administration

Attribution aux provisions sur titres

Augmentation de la fortune
Actifs

33449.39

66889.77

54597.37

18785.30

220000.00

3180019.15 *

16957.85

1080000.00

90000.00

20000.00

19450.75

2470491.58

2540.90

3750.65

3573740.98

3573740.98

\section{Charges}

Produits

104203.75

79550.10

24000.00

246362.95

57.90

320200.00

48224.05

82000.00

3750.65

454174.70

* Valeur boursière au 31 décembre 2006: Fr. 3753 128.-. 